\title{
Comportamento de híbridos de couve-flor em plantio direto sob manejo fitossanitário convencional e alternativo no cultivo de inverno/primavera em Santa Catarina
}

\author{
João Vieira Neto' ${ }^{1}$ Francisco Olmar Gervini de Menezes Júnior' e Paulo Antônio de Souza Gonçalves
}

\begin{abstract}
Resumo - O objetivo do estudo foi avaliar o desempenho de híbridos de couve-flor em sistema de manejo fitossanitário convencional e alternativo. Dois experimentos foram realizados na Estação Experimental de Ituporanga (Epagri/EEltu), em agosto de 2018 e 2019. Em cada manejo foi adotado delineamento de blocos ao acaso com quatro repetições, tendo como parcelas vinte plantas de cada cultivar, parcela útil constituída por seis plantas centrais. As mudas foram transplantadas sobre palhada de aveia e ervilhaca. Avaliaram-se aspectos referentes ao rendimento agronômico, à qualidade das inflorescências, a danos causados por pragas e por doenças incidentes nas plantas, especialmente as podridões bacterianas e fúngicas. Os híbridos de couve-flor Alpina, Verona e Júlia são os mais indicados para a semeadura em cultivos de inverno/primavera, na região do Alto Vale do Itajaí, SC. O controle de pragas e doenças é possível com produtos fitossanitários de menor toxicidade.
\end{abstract}

Termos para indexação: agrotóxicos; Brassica oleracea var. botrytis; produtividade; sistemas de produção; manejo alternativo de pragas e doenças.

\section{Cauliflower hybrids in no-tillage under conventional and alternative phytosanitary management in winter/spring cultivation in Santa Catarina}

\begin{abstract}
The objective of this study was to evaluate the yield of cauliflower hybrids cultivated under conventional and alternative phytosanitary management system. Two experiments were carried out at Ituporanga Experimental Station (Epagri/ EEltu) in August 2018 and 2019. In each management a randomized block design with four replications was adopted, with plots of twenty plants of each cultivar, useful plot consisting of six central plants. The seedlings were planted over oat and vetch straw. Aspects related to agronomic yield, quality of inflorescences, damage caused by pests and plant diseases, especially bacterial and fungal rot, were evaluated. The cauliflower hybrids Alpina, Verona and Julia are the most suitable for sowing in winter/spring crops, in the Alto Vale do Itajaí region, SC. The control pests and diseases is possible with phytosanitary products of lower toxicity.
\end{abstract}

Index terms: pesticides; Brassica oleracea var. botrytis; productivity; production systems; alternative pest and disease management.

A couve-flor representa importante atividade econômica para Santa Catarina. A safra catarinense é caracterizada por colheitas realizadas no outono/ inverno e inverno/primavera, notadamente em pequenas propriedades com utilização de mão de obra familiar. A entressafra dessa hortaliça ocorre de fevereiro a junho, período em que a oferta é reduzida. Isso se deve, entre outros fatores, à carência de informações técnicas na recomendação de cultivares adaptados às condições edafoclimáticas das regiões de cultivo.

A espécie é naturalmente sensível ao clima, exigindo-se temperaturas mais amenas e manejos culturais específicos. Diante disso, houve o desenvolvimento de híbridos que apresentam condições de produção adequadas em climas mais quentes, o que permite seu cultivo durante todo o ano (MORAIS JÚNIOR et al., 2012). No entanto, o clima de verão com altas precipitações ocasiona maiores perdas por doenças na lavoura e em pós-colheita em couve-flor. Peruch \& Silva (2006) relataram a escassez de trabalhos de pesquisa para estudar o comportamento de híbridos constantemente lançados no mercado.

Normalmente as brássicas são cultivadas em sistema convencional com a utilização de agrotóxicos, cujos principais alvos são: controle de doenças causadas por fungos, bactérias e insetos. Contudo, esta prática proporciona impactos negativos ao ambiente e à saúde de agricultores e consumidores (LOPES \& ALBUQUERQUE, 2018). O objetivo foi avaliar o rendimento e o comportamento de híbridos de couve-flor em sistema de manejo fitossanitário convencional com uso de agrotóxicos e alternativo, no período de inverno/primavera.

Os experimentos foram conduzidos na Estação Experimental de Ituporanga (Epagri/EEltu), SC, latitude de $27^{\circ} 38^{\prime}$ S, longitude de $49^{\circ} 60^{\prime} \mathrm{W}$ e altitude de 475 .

Recebido em 20/7/2020. Aceito para publicação em 22/10/2020.

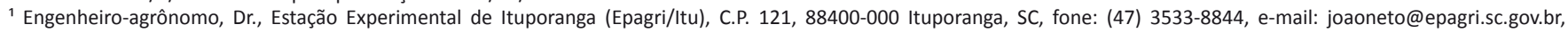
franciscomenezes@epagri.sc.gov.br, pasg@epagri.sc.gov.br. 
metros acima do nível do mar. Segundo a classificação de Köppen, o clima local é do tipo Cfa, caracterizado como clima temperado chuvoso e quente. Os tratamentos consistiram em cinco cultivares de couve-flor: Alpina (Topseed, inverno), Júlia (Sakata, inverno), Serena (Tecnoseed, meia estação), Vera (Tecnoseed, meia estação), Verona (Seminis, verão), cultivados em dois sistemas de manejo fitossanitário (convencional e alternativo). Os tratamentos dos cultivares foram conduzidos independentemente em cada sistema de manejo fitossanitário.

O manejo convencional no controle de pragas foi realizado com duas pulverizações com $0,15 \mathrm{ml} \mathrm{L}^{-1}$ de Eleitto ${ }^{\circledR}$ (acetamiprido $167 \mathrm{~g} \mathrm{~L}^{-1}+$ etofenproxi $300 \mathrm{~g}$ $\left.\mathrm{L}^{-1}\right)$, três com $0,3 \mathrm{ml} / \mathrm{L}$ de Decis $25 \mathrm{EC}$ (deltametrina $25 \mathrm{~g} \mathrm{~L}^{-1}$ ) e três com $2 \mathrm{ml}$ $\mathrm{L}^{-1}$ de Provado (imidacloprido 200 $\mathrm{L}^{-1}$ ). No controle convencional de doenças foram realizadas quatro pulverizações com $0,2 \mathrm{ml} \mathrm{L}^{-1}$ de Score (difenoconazol $250 \mathrm{~g} \mathrm{~L}^{-1}$ ) e quatro com $1,25 \mathrm{ml} \mathrm{L}^{-1}$ de Revus $^{\bullet}$ (mandipropamida $250 \mathrm{~g} \mathrm{~L}^{-1}$ ). Enquanto que, no manejo alternativo para controle de pragas foram quatro pulverizações com $2 \mathrm{ml} / \mathrm{L}$ de Azamax (Azadiractina $\left.12 \mathrm{~g} \mathrm{~L}^{-1}\right)$, quatro pulverizações com $3 \mathrm{ml} / \mathrm{L}$ de Assist ${ }^{\circ}$ (Óleo mineral $756 \mathrm{~g}$ $\left.\mathrm{L}^{-1}\right)+5 \mathrm{~g} / \mathrm{L}$ de Bugran ${ }^{\circ}$ (terra de diatomáceas, composto por $98,58 \%$ de $\mathrm{SiO}_{2}$ ) e no controle de doenças, duas aplicações com $2 \mathrm{ml} / \mathrm{L}$ de Enxofre (S 450g L-1) e seis com $3 \mathrm{~g} \mathrm{~L}^{-1}$ de sulfato de cobre. Nos dois manejos as aplicações foram preventivas semanais.

Foi adotado delineamento de blocos ao acaso com quatro repetições, parcelas com 20 plantas e área útil constituída por seis plantas centrais. As mudas foram transplantadas com quatro a cinco folhas definitivas, no espaçamento de $0,5 \mathrm{~m} \times 0,8 \mathrm{~m}$ em agosto de 2018. Em agosto 2019, o ensaio foi repetido adotando-se os mesmos procedimentos realizados no ano anterior. Os experimentos foram estabelecidos em sistema de plantio direto sob palha de aveia e ervilhaca, semeadas em abril de 2017 e 2018, nas quantidades respectivamente de 60 e $80 \mathrm{~kg}$ de semente ha-1 para cada espécie. A adubação foi efetuada conforme a Comissão de Química e Fertilidade do Solo (CQFS-RS/SC, 2016) para a cultura em sistema de plantio direto.

As colheitas foram realizadas semanalmente, quando as inflorescências atingiram o tamanho adequado para embalagem em bandeja de poliestireno expandido com dimensão de $15 \mathrm{~cm} x$ $15 \mathrm{~cm} \times 2 \mathrm{~cm}$. As seguintes características foram avaliadas: rendimento (número de inflorescências colhidas por ha-1); produtividade ( $\mathrm{t} \mathrm{ha}^{-1}$ ) e peso médio das inflorescências ( $\mathrm{kg}$ planta $\left.^{-1}\right)$. $O$ índice de qualidade visual das inflorescências (MELO et al., 2010) foi determinado com escala de notas variando de 1 a 5 (1= não comerciais, extremamente defeituosas, $2=$ comerciais defeituosas, $3=$ moderadamente defeituosas, $4=1$ evemente defeituosas, $5=$ sem defeitos aparentes). Os principais defeitos das inflorescências são: presença de podridão, folhas, pelos, manchas cor vinho e deformações.

As variáveis referentes à fenologia foram o ciclo (número de dias entre a semeadura a última colheita); precocidade média (número de dias entre a semeadura até a primeira colheita) e o período de colheita, obtido pela diferença, em dias, entre a última e primeira coIheita realizadas. As variáveis com dados fitossanitários foram o percentual de plantas doentes (podridão no caule e na cabeça) e o número médio de folhas por planta com mais de $10 \%$ de danos provocados por pragas desfolhadoras. Os dados coletados foram submetidos à análise de variância e as médias comparadas pelo teste de Scott-Knott, a 5\% de probabilidade, utilizando-se o software livre "R" (R CORE TEAM, 2017).

No manejo fitossanitário convencional, o cultivar Alpina obteve melhor produção $\left(23.958 \mathrm{ha}^{-1}\right)$ e qualidade de cabeça (notas para o índice de aspecto visual de 3,9$)$, seguido pelos cultivares Verona (23.000ha-1 e nota de 3,5) e Júlia (22.917 ha-1 e nota de 3,9) (Tabelas 1 ). Já, no manejo alternativo, as melhores produção e qualidade de inflorescências foram alcançadas pelos cultivares Alpina $\left(23.438 \mathrm{ha}^{-1}\right.$ e nota de 4,0$)$ e Verona $\left(23.125 \mathrm{ha}^{-1}\right.$ e nota de 3,6$)$, seguidas pelo cultivar Júlia $\left(22.708 \mathrm{ha}^{-1}\right.$ e nota de 4,1) (Tabelas 1).

Embora com boa produção no manejo convencional (Tabela 1 ), os cultiva- res Serena ( 21.500 cabeças ha-1 $^{-1}$ e Vera (20.833 cabeças ha-1), apresentaram menor qualidade de cabeças respectivamente com notas de 2,3 e 3,1. Resultado semelhante foi observado no manejo alternativo (Tabela 1) para estes cultivares, cujas produções e notas foram respectivamente: Serena (21.250 cabeças ha-1 $, 2,2)$, Vera (20.625 cabeças $\left.\mathrm{ha}^{-1}, 2,6\right)$.

Verona apresentou maior precocidade (média de 119 dias), com antecipação do ciclo em até 20 dias, em ambos os manejos, situado entre os cultivares mais produtivos e de melhor qualidade. Morais Júnior et al. (2012) e Monteiro et al. (2010) observaram valores de precocidade média de 112 e 119 dias, respectivamente, para Verona, próximos aos observados no presente estudo. Verona é classificado como cultivar de ciclo médio (110 a 130 dias), pelo critério proposto por Maluf \& Corte (1990), citado por Morais Júnior et al. (2012).

Os danos por doenças não foram tão expressivos nos cultivares mais produtivos, cujas perdas ficaram abaixo de dez por cento em ambos os manejos. No entanto, dentre os cultivares menos produtivos as perdas por doenças atingiram respectivamente 16,7 e $17,5 \%$ no manejo convencional e alternativo (Tabelas 1). Peruch \& Silva (2006) não constataram diferenças quanto à produtividade para os híbridos AF-817, AF649, AF-567, Legacy e Majestic Crown. Porém, nos dados de Peruch \& Silva (2006) foram observados índices baixos de incidência e de severidade para podridão negra e alternariose, respectivamente com médias de 0,3 e $20 \%$.

Durante as avalições foram constadas presenças de Plutella xylostella e Trichoplusia ni. No entanto, assim como relatado por Vieira Neto et al. (2020), em geral os danos provocados por estas lagartas não afetaram expressivamente a qualidade das inflorescências dos cultivares mais produtivos.

Os híbridos Alpina, Verona e Júlia são os mais indicados para a semeadura em cultivos de inverno/primavera, na região do Alto Vale do Itajaí, SC. É possível realizar o controle de pragas e doenças com produtos fitossanitários de menor toxicidade. 
Tabela 1. Médias de duas safras 2018/19 para número de cabeças por hectare (Rend.), peso médio da cabeça (PMC), índice de aspecto visual das inflorescências (IAV), ciclo, precocidade média (PM), período de colheita (PC), percentual de plantas doentes (PD), desfolha por lagartas (Desf.) para couve-flor no manejo convencional e alternativo. Ituporanga, SC, Epagri, 2018 e 2019

Table 1. Average of two 2018/19 harvests for number of heads per hectare (Rend.), Average head weight (PMC), visual aspect index of inflorescences (IAV), cycle, average precocity (PM), harvest period (PC), percentage of sick plants (PD), defoliation by caterpillars (Desf.) for cauliflower under conventional and alternative management. Ituporanga, SC, Epagri, 2018 and 2019

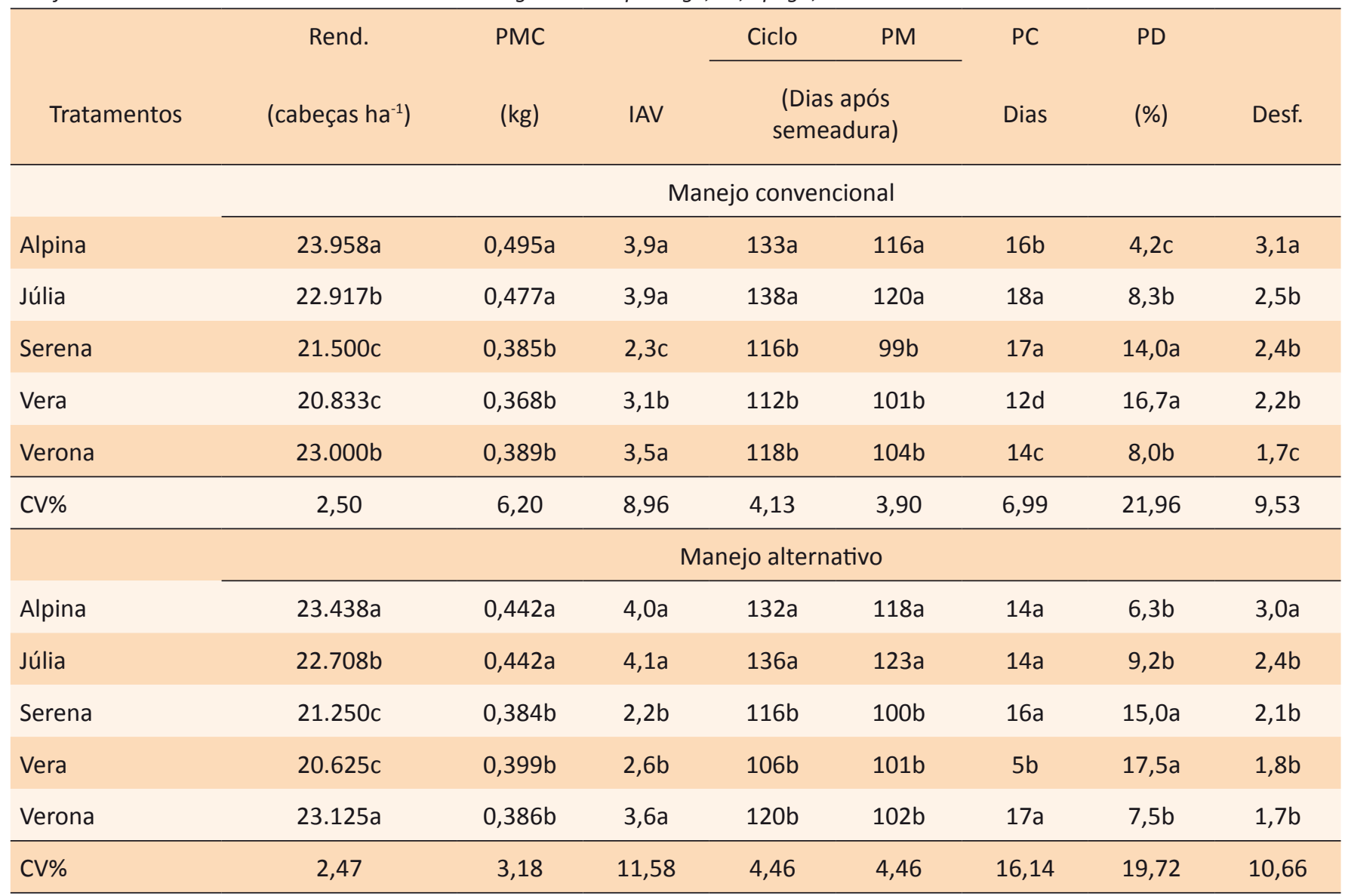

Médias não seguidas da mesma letra na coluna diferem entre si pelo teste de Scott-Knott a $5 \%$ de probabilidade. NS: Não significativo pelo teste $\mathrm{F}$ a $5 \%$.

\section{Referências}

CQFS-RS/SC. Manual de calagem e adubação para os estados do Rio Grande do Sul e de Santa Catarina. 11.ed. Santa Maria: Sociedade Brasileira de Ciências do Solo - Núcleo Regional Sul, 2016. 376p.

LOPES, C.V.A.; ALBUQUERQUE, G.S.C. Agrotóxicos e seus impactos na saúde humana e ambiental: uma revisão sistemática. Saúde em Debate, v.42, p.518-534, 2018.

MELO, R.A.C.; MADEIRA, N.R.; PEIXOTO, J.R. Cultivo de brócolos de inflorescência única no verão em plantio direto. Horticultura Brasileira, v.28, n.1, p. 23-28, 2010. Disponível em: http://www.scielo.br/pdf/hb/v28n1/ a05v28n1.pdf. Acesso em: 09 set. 2019.

MONTEIRO, B. C. B. A; CHARLO, H. C. O.;
BRAZ, L.T. Desempenho de híbridos de couve-flor de verão em Jaboticabal. Horticultura Brasileira, v.28, n.1, p. 115-119, 2010. Disponível em: http://www.scielo.br/pdf/ hb/v28n1/a22v28n1.pdf. Acesso em: 10 set. 2019.

MORAIS JÚNIOR, O.P. de.; CARDOSO, A.F.; LEÃO, É.F.; PEIXOTO, N. Desempenho de cultivares de couve-flor de verão em Ipameri. Ciência Rural, v.42, n.11, p.1923-1928, 2012. Disponível em: http://www.scielo.br/pdf/ cr/2012nahead/a30512cr6583.pdf. Acesso em: 18 jul. 2019.

PERUCH, L.A.M.; SILVA, A.C.F. da. Avaliação de híbridos de repolho, couve-flor e brócolis sob cultivo orgânico, em duas épocas de plantio, no Litoral Catarinense. Agropecuária Catarinense, Florianópolis, v.19, n.3, p.8790, 2006. Disponível em: file://C:/Users/
joaoneto/Downloads/Revista\%20agropecuaria\%20catarinense\%20\%20nov_2006.pdf. Acesso em: 20 jul. 2019.

R CORE TEAM. R: A language and environment for statistical computing. $\mathrm{R}$ Foundation for Statistical Computing, Vienna, Austria. 2017. Disponível em: https://www.R-project.org/. Acesso em: 25 jul. 2018.

VIEIRA NETO, J.; GONÇALVES, P.A. de S.; MENEZES JÚNIOR, F.O.G. de; ARAÚJO, E.R. de; KURTZ, C. Desempenho de cultivares de couve-flor em diferentes manejos fitossanitários em cultivos de verão/outono, sob plantio direto, em Santa Catarina. Vértices, v. 22, p. 82-91, 2020. Disponível em: http:// essentiaeditora.iff.edu.br/index.php/vertices/article/view/14576/12692. Acesso em: 17 jul. 2020. 